\title{
Design and Performance of an Open Jet Wind Tunnel for Aero- Acoustic Measurement
}

\author{
T. P. Chong*, P. F. Joseph and P. O. A. L. Davies \\ ISVR, University of Southampton, University Road, Southampton, SO17 1BJ, UK
}

\begin{abstract}
This paper presents the design and performance of an open jet, blow down wind tunnel that was newly commissioned in the anechoic chamber at the ISVR, University of Southampton, UK. This wind tunnel is intended for the measurement of airfoil trailing edge self-noise but can be extended to other aeroacoustic applications. With the primary objectives of achieving acoustically quiet and low turbulence air jet up to $120 \mathrm{~m} / \mathrm{s}$ through a $0.15 \mathrm{~m} \times 0.45 \mathrm{~m}$ nozzle, several novel noise and flow control techniques were implemented in the design. Both the acoustical and aerodynamic performances of the open jet wind tunnel were examined in detail after its fabrication. It is found that the background noise of the facility is adequately low for a wide range of exit jet velocity. The potential core of the free jet is characterized by a low turbulence level of about $0.1 \%$. Benchmark tests by submerging a NACA0012 airfoil with tripped and untripped boundary layers at $0^{\circ}$ and $10^{\circ}$ angles of attack respectively into the potential core of the free jet were carried out. It was confirmed that the radiating airfoil trailing edge self-noise has levels significantly above the rig noise over a wide range of frequencies. The low noise and low turbulence characteristics of this open jet wind tunnel are comparable to the best facilities in the world, and for its size it is believed to be the first of its kind in the UK.
\end{abstract}

Keywords: Wind Tunnel Design, Silencer, Trailing Edge Noise

* - Correspondence author

\section{Current address:}

College of Engineering, Design and Physical Sciences, Brunel University London, Uxbridge, UK, UB8 3PH Tel: +44-1895 266370, Email: t.p.chong@brunel.ac.uk 


\section{Introduction}

Until recently the main source of engine noise from commercial aircraft has been from the jet. With the advance of more effective low noise engine technologies, such as ultra high bypass ratio engine and lower speed fans, significant reductions in the jet noise have been realized. By contrast, due to a relatively poorer understanding of fan broadband noise, it has become a dominant noise source in modern aero-engines. One of the dominant broadband noise generation mechanisms is due to the interaction of the turbulent boundary layer with the trailing edge of the fan blades. In this case, the vortical disturbances of the turbulent boundary layer scatter at the sharp trailing edge into sound. Trailing edge self noise is also a dominant noise generation mechanism on aircraft wings and wind turbines. The ability to predict and characterize trailing edge self-noise is therefore important in order for its understanding and mitigation. A number of theoretical and computational models of trailing edge self-noise may be found in the literature [1-5]. However, experimental studies of trailing edge noise are comparatively scarce [6-8], most likely due to the numerous difficulties in obtaining accurate trailing edge self-noise measurements. The main difficulty with this measurement is the high levels of background noise such as from the fan that is usually used to generate the air-flow, structural vibration noise, and the noise induced by flow through various components of the test tunnel. These extraneous noises, especially in high Reynolds number experiments, can easily mask the relatively weak broadband trailing edge self-noise.

Essential requirements of an open jet wind tunnel for aeroacoustic measurements are that, most importantly, the trailing edge self-noise should be significantly greater than the background noise (more than $10 \mathrm{~dB}$ ); second, the incoming flow should be of sufficiently low turbulence intensity to eliminate the noise generated through its interaction with the leading edge. A number of high quality aeroacoustic wind tunnels exist around the world that meet these requirements at low to moderate Reynolds numbers [9-11]. However, the design of an aeroacoustic wind tunnel that matches the operating Reynolds numbers of an aircraft turbo-engine inlet fan, typically from 1 to 3 x $10^{6}$ (based on axial velocities at $30 \%$ from blade root to blade tip respectively) at approach [12], and yet still retain low background noise and low turbulence intensity is significantly more difficult to achieve. This is the objective of the wind tunnel design presented here. This paper presents the design principles of the open jet wind tunnel, with special emphasis given to its acoustical and aerodynamic performances. Major components such as the silencer, diffuser, settling chamber and nozzle will be described in detail. Calibration results of the facility background noise and the exit jet turbulence levels and flow uniformity will also be included. Finally, typical measurements of the 
trailing edge noises from a symmetric NACA0012 in the quiet configuration of $0^{\circ}$ and $10^{\circ}$ angles of attack are presented and are shown to be between $10 \mathrm{~dB}$ and $30 \mathrm{~dB}$ above the background noise level. The low noise and low turbulence characteristics of this open jet wind tunnel are comparable to, or better than, the best facilities in the world. This facility is believed to be the first of its kind in the UK.

\section{Design Criteria}

The open jet wind tunnel is designed to fulfil the following acoustic and aerodynamic criteria:

1. Airfoil trailing edge self-noise must be at least $10 \mathrm{~dB}$ above the facility noise over a wide band of frequencies.

2. Maximum Mach number of about 0.3.

3. Typical turbulence intensity of less than $0.5 \%$.

4. The jet working section is situated in the ISVR's large anechoic chamber $(8 \mathrm{~m} \times 8 \mathrm{~m} \times 8 \mathrm{~m})$ for the free field measurement of the self-noise of objects located in the potential core of the jet.

5. The air must be adequately exhausted from the anechoic chamber.

The wind tunnel is designed to deliver a maximum mass flow rate of about $8 \mathrm{~kg} / \mathrm{s}$ corresponding to a Mach number of about 0.3 over a nozzle area of $0.0675 \mathrm{~m}^{2}$. The nozzle was chosen to have a large contraction ratio (CR) in order to reduce lateral velocity fluctuations and hence reduce the turbulence level of the exit jet. For such purpose the CR is usually taken as 20-25:1, which gives the inlet area of the nozzle between $1.35 \mathrm{~m}^{2}$ and $1.70 \mathrm{~m}^{2}$. Air is supplied from three tanks with a total volume of $30 \mathrm{~m}^{3}$ at $2000 \mathrm{kPa}$ pressure, which is released through a control valve. The use of tanks supplied by a compressor is thought to be a quieter method of delivering air than the use of a fan, although the latter has the advantage that it offers continuous operation. Table 1 summarizes the estimated running times of the open jet wind tunnel at different mass flow rates/jet speeds with the nozzle exit area of $(0.15 \times 0.45) \mathrm{m}^{2}$.

\section{Layout of the Open Jet Wind Tunnel}

The layout of the quiet open jet facility is shown in Fig. 1. Air is stored in tanks at $2000 \mathrm{kPa}$ located upstream of the control valve. The control valve is located in the roof space of the anechoic chamber, which reduces the downstream air pressure to $200 \mathrm{kPa}$. The air is then expanded in the $8^{\prime \prime}$ $(20 \mathrm{~cm}$ ) diameter steel pipe through a wide-angle conical diffuser into a $1.3 \mathrm{~m} \times 2.4 \mathrm{~m} \times 4.1 \mathrm{~m}$ three 
pass silencer to attenuate the noise generated by the valve. After leaving the silencer the air is accelerated vertically towards the ground through a $3: 1$ contraction ratio (CR) 2D nozzle into a 0.33 $\mathrm{m} \times 1.3 \mathrm{~m} \times 4 \mathrm{~m}$ duct located in the wall of the anechoic chamber. The air then turned by a $90^{\circ}-$ curved diffuser and is expanded from an area of $0.33 \mathrm{~m} \times 1.3 \mathrm{~m}$ to $1.3 \mathrm{~m} \times 1.3 \mathrm{~m}$ over an axial distance of $1.4 \mathrm{~m}$. The straightness and uniformity of the air flow are improved by the use of a honeycomb and three fine woven wire mesh screens before entering a $1.3 \mathrm{~m} \times 1.3 \mathrm{~m} \times 2 \mathrm{~m}$ splitter silencer, which also acts to settle the flow. Finally, further flow conditioning is achieved by the use of additional honeycomb and fine woven wire mesh screens before the air accelerates through a 3D 25:1 CR nozzle. The nozzle has a rectangular exit area of $0.15 \mathrm{~m} \times 0.45 \mathrm{~m}$. The resulting maximum Reynolds number based on the hydraulic diameter at the nozzle exit is $1.5 \times 10^{6}$. The nozzle exit is situated at the centre of the anechoic chamber. As shown in Fig. 1, the air jet is finally exhausted through a hole in the chamber wall directly opposite the nozzle into a large adjoining room from where the air leaves through doors and windows to the outside of the building. The distance between the nozzle and the exhaust hole is about $4 \mathrm{~m}$. The jet was slowed down and diffused inside the adjoining room. The transmission of residual noise from the adjoining room back to the anechoic chamber is reduced by the acoustic wedges on the chamber wall. Hence the excess noise is contained within the adjoining room and will not be picked up by the microphones inside the anechoic chamber. In the remainder of this section detailed descriptions of the various parts of the open jet wind tunnel are presented.

\section{Control valve}

As outlined above, a control valve was installed to regulate the flow rate of the compressed air into the wind tunnel. The ability of the control valve to maintain a constant and steady pressure is essential to ensure the stability of the exit jet velocity. An unfortunate consequence of the use of storing the air at high pressures and reducing it across a valve is the associated generation of noise due to the large pressure drop across it. Two approaches were employed to reduce this noise source. The first is to use a control valve with an innovative noise-control design; the second is to introduce a silencer downstream of the control valve to attenuate the noise levels. The latter approach will be discussed in detail in the next section.

The control valve chosen for this rig was the WhisperFlo Trim, manufactured by Fisher. It is sized to withstand $2000 \mathrm{kPa}$ upstream pressure and reduce to a maximum downstream pressure of $200 \mathrm{kPa}$ across the valve. The main noise-management techniques adopted by this control valve are as follows: First, it divides the pressure drop over two stages, where the largest pressure drop occurs at the first stage to contain the noise locally. Second, a unique passage profile inside the valve is 
also introduced to reduce flow turbulence and dissipate the flow-induced noise. Third, each individual exit jet of the control valve is aligned such that jet coalescences are delayed until each jet becomes fully-developed to shear flow. Hence, the mixing noise due to the merging of high-speed potential flow is reduced.

\section{Primary silencer}

Noise generated by dropping the pressure across the control valve is attenuated by the use of a large silencer. The silencer is designed to have a high transmission loss (TL) and a low aerodynamic pressure drop. It is in the form of a lined "3 pass" plenum chamber, which incorporates two $90^{\circ}$ acoustically lined bends and two $180^{\circ}$ lined bends, in addition to three straight runs of lined duct (see Fig. 1). All interior surfaces are treated with the same Basalt wool dissipative liner of $150 \mathrm{~mm}$ thickness with a facing cloth (woven glass fabric) to inhibit flow delamination and a (mainly structural) facing of perforated metal. The baffle plates are of $3 \mathrm{~mm}$ thick mild steel in order to provide a sufficient transmission loss between successive "passes". The walls are made of $20 \mathrm{~mm}$ thick plywood in order to reduce to acceptable levels the direct structural flanking transmission (as opposed to "radiation bypass" flanking) within the silencer.

Measurement of the primary silencer transmission loss was performed. The ratio of sound powers at the inlet and outlet was measured using a $\mathrm{B} \& \mathrm{~K}$ intensity probe. The measurement is compared with the theoretical predictions of Cummings [13], as shown in Fig. 2. Satisfactory agreement between the experimental result and prediction can be seen in the figure which shows a 50-60 dB measured and predicted transmission loss in the frequency range from $300 \mathrm{~Hz}$ to 4000 $\mathrm{Hz}$.

\section{$90^{\circ}$-curved diffuser}

Due to space constraints, air leaving the $4 \mathrm{~m}$ vertical straight air duct must be rapidly turned $90^{\circ}$ to orientate the air-flow along the wind tunnel axis (see Fig. 1). As mentioned earlier the inlet area of the nozzle should be between $1.35 \mathrm{~m}^{2}$ and $1.70 \mathrm{~m}^{2}$. With the exit area of the air passage fixed at $0.43 \mathrm{~m}^{2}(0.33 \mathrm{~m} \times 1.3 \mathrm{~m})$, an area expansion ratio of between 3 and 4 is therefore required. A diffuser is generally used to recover static pressure and to expand flow area. The $90^{\circ}$-curved diffuser in the current design serves the purpose of simultaneously expanding the area and turning the flow. It is of secondary importance for pressure recovery since the pressure at the curved diffuser inlet is already excessive at about $80 \mathrm{kPa}$. Unlike a straight diffuser, an effective curved diffuser is more difficult to design due to the existence of centrifugal forces that can produce detrimental secondary flows that tend to destabilize boundary layer growth. The combination of the 
pressure-driven secondary flow and the streamwise adverse pressure gradient makes the boundary layer more susceptible to flow separation, especially at the inner-wall region (convex part). Turbulence and noise produced by the creation of separated flow may substantially degrade the effectiveness of the wind tunnel and must therefore be suppressed. Much of the effort in the design of this wind tunnel was therefore dedicated to preventing flow separation in the $90^{\circ}$-curved diffuser, as discussed below.

For the design of a curved diffuser, three dimensionless parameters are of importance: the arearatio $\left(A R, W_{1} / W_{2}\right)$, scaled inner wall length $\left(L_{\text {in }} / W_{1}\right)$ and the turning angle $(\Delta \phi)[14]$, where $W_{1}$ and $W_{2}$ are the widths of the curved diffuser inlet and outlet respectively and Lin is the inner-wall length. It has been demonstrated that, to maintain separation-free at the inner-wall region, the allowance for higher $A R$ and lower $L_{\text {in }} / W_{1}$ decreases when $\Delta \phi$ increases [14]. In other words, to maintain a steady diffusing flow, the diffuser is required to be longer and hence more floor space is needed to accommodate it. However, for the current design, there is a severe space limitation and the curved diffuser must be necessarily short, resulting in an undesirably abrupt curvature of the inner-wall. With the available space and the required curved diffuser expansion ratio of 3-4 as the only two constraints, the $90^{\circ}$-curved diffuser was designed accordingly. The dimensions, $W_{1}, W_{2}$ and $L_{\text {in }}$ were eventually chosen to $0.33 \mathrm{~m}, 1.3 \mathrm{~m}$ and $0.849 \mathrm{~m}$, respectively. This configuration yields $L_{\text {in }} / W_{1}$ as 2.57 and $W_{2} / W_{1}$ (or $A R$ ) as 3.94 with $\Delta \phi=90^{\circ}$. If these values are substituted into the classical design curves for a curved diffuser with circular-arc centreline (shown in Fig. 2 of Ref. [15]), the current diffuser with short but large $A R$ and $\Delta \phi$ values is predicted to fall into the severe stall regime for a wide range of Reynolds numbers.

To achieve a non-separating boundary layer with this geometry the diffusing flow should be controlled by the introduction of flow control devices. However, this will most likely be achieved at the expense of a reduced pressure recovery. Several passive flow control methods have been proposed to suppress flow separation, which include the use of splitter vanes and honeycombs and woven wire mesh screens. A suitable design of the $90^{\circ}$-curved diffuser that incorporates these features was achieved by performing a parametric performance study on a 1/6th scale-model driven by a centrifugal blower. Various combinations of the aforementioned flow control devices were investigated, as shown in the schematic of Fig. 3a. Also shown in the figure is the coordinate system $\left(y_{0}, z_{0}\right)$ for the cross-sectional plane of the $90^{\circ}$-curved diffuser exit. A Pitot tube was used to measure the cross-sectional total pressure contours at $5 \mathrm{~cm}$ from the diffuser model exit. The improved levels of flow uniformity obtained following the application of the flow control devices are shown in Fig. $3 b$ and c. 
Fig. $3 b$ shows the pressure contours in the absence of splitters, honeycomb and screens. It is apparent that a significant total pressure deficit (blue colour) encompasses more than $50 \%$ of the flow area at the exit. This pressure deficit region is associated with the large-scale, non-recoverable flow separation that originated from the inner-wall region. A consequence of this "dead flow" region shown in Fig. $3 b$ is that most of the mass flow is transferred to a fast stream flow towards the outer-wall region (shown in red). Without flow control treatment, incorporating the current $90^{\circ}$ curved diffuser into a wind tunnel would require a substantial distance before the separated flow from the diffuser inner-wall reattaches again. Following extensive testing, it was shown that three equally spaced splitter vanes, a honeycomb at the diffuser exit followed by three fine woven wire mesh screens, with a cumulative pressure drop of $5.5 q$ ( $q$ is the dynamic pressure, see Eq. (2)) can suppress effectively the boundary layer separation at the inner-wall*. This is confirmed in Fig. 3c where the exit flow was found to be reasonably uniform over most of the exit area (note that the contour scale in Fig. 3c is reduced to improve the resolution, i.e. if the same larger contour scale as in Fig. $3 \mathrm{~b}$ is used instead, a visually more uniform pressure distribution will be obtained). A detailed discussion of the physical mechanism by which the screens and guide vanes inhibit flow separation is beyond the scope of the current paper and is reported elsewhere [16].

This arrangement of splitters and screens was adopted in the full-size $90^{\circ}$-curved diffuser, whose performance was tested using a rake of nine Pitot-tubes covering the distance between the outer to inner-walls of the diffuser $(\sim 1.3 \mathrm{~m})$ to simultaneously measure the exit flow total pressures. Since the full-size and scale model experiments were performed at different flow speeds, direct comparison of the data between the two is not possible. A more meaningful approach is to determine the velocity deviations, $U_{\mathrm{dev}}$, of the measured velocity compared with the flow at the outer-wall region where it takes a maximum value. This quantity can be expressed as:

$$
U_{d e v}=\frac{U_{\left(Y_{o} \rightarrow 0, Z_{o}=0.5\right)}-U_{\left(Y_{o}, Z_{o}=0.5\right)}}{U_{\left(Y_{o} \rightarrow 0, Z_{o}=0.5\right)}}
$$

where $U_{\left(Y_{o} \rightarrow 0, Z_{o}=0.5\right)}$ is the velocity at the outer wall region of the centre-plane, $Z_{o}=0.5$; whereas $U_{\left(Y_{o}, Z_{o}=0.5\right)}$ is the velocity from the outer to inner walls (in $Y_{o}$ direction), also at $Z_{o}=0.5$. Here $Y_{o}$ and $Z_{o}$ are the distances $y_{o}$ and $z_{o}$ normalized on their respective diffuse exit widths. Fig. 4a compares the aerodynamically treated full-size ( $\square$ ) and scale-model (o) velocity deviations at $Z_{o}=0.5$ of the $90^{\circ}$-curved diffuser exits. Also shown in the figure is the corresponding velocity deviation for a bare, untreated scale-model $90^{\circ}$-curved diffuser $(\Delta)$. Good agreement is observed between the flow

\footnotetext{
* It is also observed that the exit flow uniformity can be further improved by adding more guide vanes and larger pressure drop at the curved diffuser exit. The suggested combination is a good balance of effective flow control and minimal construction complexity.
} 
uniformities of the full-size and scale-model treated diffusers. For the treated case, the velocity deviations of exit flow from the outer to the inner-walls for both of the full-size and scale-model diffusers are significantly lower than the untreated case. This implies that the addition of splitter vanes, honeycomb and pressure-reducing screens has successfully maintained uniform flow over a relatively wide range of Reynolds numbers by inhibiting large-scale flow separation at the innerwall. Finally, error bars corresponding to the variations in exit velocity at different spanwise locations $\left(Z_{\mathrm{o}}\right)$ from the outer to inner-walls are shown in Fig. 4b. The deviations are generally small which implies that a satisfactory two-dimensional exit flow has been achieved by the uses of both guide vanes and mesh screens.

\section{Settling chamber / secondary silencer}

As shown in Fig. 1, a straight silencer duct section was installed following the $90^{\circ}$-curved diffuser to further smoothen and quieten the flow before it enters the nozzle. This settling chamber has dimensions of $1.3 \mathrm{~m} \times 1.3 \mathrm{~m} \times 2 \mathrm{~m}$. Honeycomb and screens were also introduced at the settling chamber inlet and outlet to further smooth the flow ${ }^{\dagger}$. Honeycomb is primarily used to straighten the flow and to reduce lateral velocity fluctuations. Since the honeycomb is less capable of reducing the streamwise component of the flow fluctuation and non-uniformity (eddies smaller than the cell size), screens were also inserted behind the honeycomb to further improve the flow quality. The most important criterion for choosing an effective screen lies in its pressure drop value. The pressure drop coefficient of a screen, $K$ can be expressed as [17]:

$$
K=\frac{\Delta p}{q}=A\left(\frac{1}{\beta^{2}}-1\right)^{B}
$$

where $\Delta p$ is the static pressure drop across the screens, $q$ is the upstream dynamic pressure and $\beta$ is the porosity, where $A$ and $B$ are constants usually taken to be 0.52 and 1 , respectively for a square woven type of mesh. Eq. (2) suggests that the pressure drop across the screen can be solely determined by its porosity. It has been suggested that $K$ should be at least 2.56 to achieve uniform flow across the screens in a wind tunnel [18]. Based on the above criterion the final values of $d$ (wire diameter), $P$ (pitch), $K$ and $\beta$ for all the screens used in the open jet wind tunnel are summarized in Table 2. Also included in the table is the summary of cell diameters and lengths for the honeycombs used in this wind tunnel.

\footnotetext{
$\dagger$ Note that honeycomb and screens at the settling chamber inlet are essentially the very same flow control devices for the $90^{\circ}$-curved diffuser.
} 
A further undesirable consequence of introducing the $90^{\circ}$-curved diffuser is that its critically unfavourable geometry is prone to generating pressure fluctuations in the flow, which can then be transmitted to distance along the wind tunnel. Furthermore, the addition of flow splitters inside the $90^{\circ}$-curved diffuser may also generate extraneous noise as a result of flow impingement and boundary layer growth. The settling chamber was therefore acoustically lined to attenuate the noise sources located downstream of the valve. The theory of Kurze [19] was used to predict the transmission loss for different combinations of lined-splitter numbers and thicknesses. In the final design, the acoustical liners consist of five parallel absorptive-line splitter plates and two linedsideliners. The splitter plates are $1800 \mathrm{~mm}$ in length and $110 \mathrm{~mm}$ in thickness; whereas the sideliners are $40 \mathrm{~mm}$ in thickness. Super-elliptical leading edge and tapered trailing edge shapes were included to ensure that smooth and attached flows exist on the splitter walls. The overall pressure drop caused by the growth of the boundary layer displacement thickness on the splitter walls was estimated to be of negligibly small at $90 \mathrm{~Pa}$. The transmission loss of this silencer was predicted to be about $35 \mathrm{~dB}$ at $2 \mathrm{kHz}$, falling to about $15 \mathrm{~dB}$ at higher frequencies.

\section{Nozzle}

The flow is accelerated rapidly in the nozzle resulting in large streamwise strain. The choice of large contraction ratio, such as in the present design (25:1 CR), which is directly proportional to the strain in the streamwise direction, is useful for minimizing flow non-uniformity and streamwise velocity fluctuations. However, the use of a large CR nozzle carries the risk of causing flow separation near the nozzle exit. In general, the radius of curvature at the ends can be kept small to avoid separation but this will result in a longer contraction length and an increase in exit boundary layer thickness. In addition, the nozzle consists of concave (at upstream) and convex (at downstream) parts so the inflection point should be designed such that the first and second derivatives of the nozzle profiles are as small as possible. The present nozzle is designed as a threedimensional, 25:1 CR nozzle. The inlet of the nozzle is a square section measuring $1.3 \mathrm{~m} \times 1.3 \mathrm{~m}$ and the outlet is rectangular shape measuring $0.15 \mathrm{~m} \times 0.45 \mathrm{~m}$. The axial length of the nozzle is 1.35 m. An isometric view of the nozzle is presented in Fig. 5a. The nozzle performance has been investigated numerically from a steady RANS calculation incorporating a $\mathrm{k}-\varepsilon$ turbulence model. As shown in the velocity contours of Fig. 5b, no flow separation is predicted inside the nozzle. 


\section{Calibration of the Open Jet Wind Tunnel}

Fig. 6 shows the completed open jet wind tunnel inside the ISVR's anechoic chamber (control valve and primary silencer are in the roof space of the chamber and are not shown in the figure). Also shown is the new coordinate system $(x, y, z)$ employed for the cross section of the nozzle exit plane. We now present the overall facility background noise characteristics for the entire rig as a function of exit jet velocity. The flow uniformity and turbulence intensity variation over the jet nozzle of the jet were also measured and are also presented below. Note that both the acoustic and aerodynamic measurement results are plotted using the new coordinate system $(x, y, z)$ as defined in Fig. 6.

\section{Analysis of background noise levels}

A microphone was placed at $(x, y, z)=(0,0.5,0)$, i.e. $0.5 \mathrm{~m}$ vertically above the centre of the cross-sectional nozzle exit plane to measure the background noise level inside the anechoic chamber at different exit jet velocities. This corresponds to a polar angle, $\theta=90^{\circ}$, where $\theta$ is the angle from the jet axis, as shown in Fig. 1. In addition, another microphone was placed at $\theta=45^{\circ}$ $(0.35,0.35,0)$ to assess the noise directivity of the exit jet. Fig. $7 \mathrm{a}$ and $\mathrm{b}$ show the narrowband (spectral density) sound pressure level at $\theta=45^{\circ}$ and $90^{\circ}$, respectively pertaining to the open jet wind tunnel over a range of jet velocities between 33.1 and $99.6 \mathrm{~ms}^{-1}$. These figures are plotted in the form of power spectral density with a $1 \mathrm{~Hz}$ bandwidth and a frequency resolution, $\Delta f$ of $6.25 \mathrm{~Hz}$. The spectra are smoothly varying and decay slowly with frequency.

It is also insightful to examine how the sound pressure level varies with jet velocity as the function of frequency. Fig. 8 shows the dependence of sound pressure level on jet velocity, $\overline{p^{2}} \propto V^{N}$ for $\theta=45^{\circ}$ and $90^{\circ}$. For $\theta=45^{\circ}$, the sound pressure level is observed to scale as $\mathrm{V}^{7.5}$ to $\mathrm{V}^{8}$ in the frequency range between $400 \mathrm{~Hz}$ and $10 \mathrm{kHz}$. This power law is classically associated with quadrupole jet mixing noise. For $\theta=90^{\circ}$, a power law of $\mathrm{V}^{6.5}$ in the frequency range $100 \mathrm{~Hz}-2$ $\mathrm{kHz}$ is observed. This velocity dependence implies that dipole aerodynamic noise sources are dominant at this measurement angle. One possible dipole noise source is due to the boundary layer being scattered at the nozzle lip. Another possible dipole noise contributor at this frequency range could be due to the noise breakout from inside of the rig. From $2 \mathrm{kHz}$ and above, the noise scales as $\mathrm{V}^{7}$ indicating the influence of jet noise. This analysis suggests that the wind tunnel noise (from the valve and secondary flows) has been reduced to nearly below that from the jet, which is an unavoidable but weak source at low Mach numbers. 
Fig. 9 shows the variation of overall sound pressure level (OASPL) with jet velocity for $\theta=45^{\circ}$ and $90^{\circ}$, respectively. Note that the A-weighted OASPL are also included for comparison with the data from other automobile and aeroacoustic wind tunnels worldwide. The figure indicates that the OASPL scales as $\mathrm{V}^{4.6}$ and $\mathrm{V}^{5.3}$, whereas the A-weighted OASPL scales as $\mathrm{V}^{7.6}$ and $\mathrm{V}^{6.8}$ at $\theta=45^{\circ}$ and $90^{\circ}$, respectively. The wind tunnel rig noise data in Fig. 9 compare favourably with the data from other automobile and aeroacoustic wind tunnels published previously [9-11]. With the assumption that the variation of sound pressure level in the azimuthal plane is small ${ }^{\ddagger}$, the OASPL

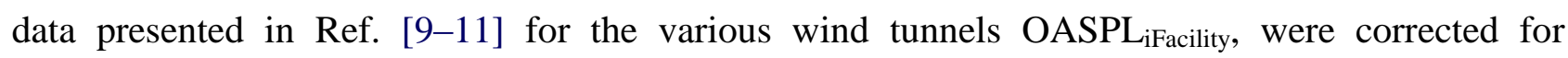
measurement distance $r_{\text {iFacility }}$ and nozzle area $A_{\text {iFacility }}$ to allow comparison with the present open jet wind tunnel by the use of the following:

$$
O A S P L_{\text {corrected }} \propto O A S P L_{\text {iFacility }}+10 \log _{10}\left(\frac{r_{\text {iFacility }}}{r_{\text {ISVR }}}\right)^{2}-10 \log _{10}\left(\frac{A_{\text {iFacility }}}{A_{\text {ISVR }}}\right)
$$

where $r_{\text {iFacility }}$ is the distance from the microphone to the centre of the nozzle exit plane of other wind tunnels; and $A_{\mathrm{iFacility}}$ is the nozzle cross-sectional areas. $A_{\mathrm{ISVR}}$ and $r_{\mathrm{ISVR}}$ are $0.0675 \mathrm{~m}^{2}$ and 0.5 $\mathrm{m}$, respectively for the ISVR open jet wind tunnel. Fig. 10 presents the distributions of A-weighted OASPL with test section velocity for a number of well-known automobile and aeroacoustic research wind tunnels around the world [9-11].

The differences in these measurements can partly be attributed to the fact that the measurement angle $\mathrm{h}$ is different for different wind tunnels presented in Fig. 10. Fig. 10 demonstrates that the Aweighted OASPL at both $\theta=45^{\circ}$ and $90^{\circ}$ for the present open jet wind tunnel is comparable with the quietest wind tunnels. The figure also shows that the A-weighted OASPL scales with $\log (\mathrm{V})$ $[7,8]$ for all the wind tunnels presented.

\section{Analysis of exit flow uniformity and turbulence characteristics}

To investigate the uniformity of the jet flow, the total pressure profiles were measured using a custom-made Pitot-tube rake. The rake consists of eleven $1.2 \mathrm{~mm}$-internal diameter steel tubes located at $15 \mathrm{~mm}$ intervals, which spans the height of the nozzle exit. By assuming the streamwise pressure gradient caused by the jet contraction to be negligible, the static pressure is approximately equal to the atmospheric pressure for the open jet. The jet velocity can thus be deduced from the measured total pressure. The Pitot tube rake was attached to a computer-controlled two-dimensional traverse mechanism. The accuracy of the traverse in both directions is within $\pm 0.01 \mathrm{~mm}$.

\footnotetext{
$\$$ For example, the OASPL at $(\mathrm{x}, \mathrm{y}, \mathrm{z})$ of $(0,0.5,0),(0,0,0.5),(0,-0.5,0)$ and $(0,0,-0.5)$ are the same.
} 
Fig. 11a shows the velocity profiles of the plane parallel to the jet axis ( $x-y$ plane) at $z=0$ between streamwise distance, $x$ of 0.1 and $1.3 \mathrm{~m}$ with an increment of every $0.1 \mathrm{~m}$. Fig. 11a shows the evolution of the jet velocity profile and its development downstream. It begins as a 'top-hat' profile close to the jet nozzle, eventually forming a fully-developed profile further downstream. This variation characterizes the spreading of the momentum-deficit shear layers that were shed from the top and bottom nozzle edges by entrainment as the flow progresses downstream. The end of the jet's potential core is clearly seen to be situated between $x=0.8$ and $0.9 \mathrm{~m}$, or $3.6-4 D_{\mathrm{h}}$, where $D_{\mathrm{h}}$ is the hydraulic diameter of the nozzle. It is expected that this length is relatively constant over the range of Reynolds numbers proposed here. The distribution of the velocity profiles averaged across the $y$-axis at different spanwise location of the nozzle exit plane at $x=0.05 \mathrm{~m}$ is shown in Fig. $11 \mathrm{~b}$. From the figure, apart from the left and right edges where mixing layers exist, the velocity profile across the nozzle exit plane is found to be uniform with an average jet velocity of $21.6 \mathrm{~ms}^{-1}$ in this example. Flow uniformity was demonstrated by the small error bars corresponding to the maximum and minimum velocity deviations inside the potential core. The results in Fig. 11a and b provide a clear indication of the extent and profile of the potential core in which the airfoil must be completely located to perform the trailing edge self-noise study to avoid the noise contribution from interaction with extraneous turbulence.

The turbulence intensity in the exit jet was measured using a TSI 1210-T1.5 miniature hot wire probe with $3.8 \mu \mathrm{m}$ diameter. The same computer-controlled traverse system was used to measure at several points from the nozzle edge to the centre in a single run. Fig. 12 shows the distribution of the turbulence intensity along the $z$-axis of the free jet at $60 \mathrm{~ms}^{-1}$ from the nozzle edge $(z=0.225 \mathrm{~m})$ to the centre $(z=0)$. This measurement was performed at a streamwise distance, $x=0.1 \mathrm{~m}$ away from the nozzle exit. Apart from the first point near the edge that is located within the shear layer, the potential core of the free jet has a typical turbulence intensity of about $0.1 \%$. This value is well below the initial target of $0.5 \%$. With such low disturbance level in the free flow, extraneous noise caused by the interaction of the jet turbulence with the airfoil leading edge is likely to be insignificant.

\section{Measurement of Airfoil Trailing Edge Noise}

A NACA0012 airfoil was situated within the potential core of the exit jet to measure its trailing edge self-noise in relation to the wind tunnel background noise. As shown in Fig. 13a, the airfoil is 
$0.15 \mathrm{~m}$ in chord and $0.45 \mathrm{~m}$ in span, and was held by side plates extended from the nozzle sidewalls. The radiated noise was measured at $0.50 \mathrm{~m}$ above the trailing edge, which corresponds to a polar angle $\theta$ equal to $90^{\circ}$.

The background noises of the open jet wind tunnel were first measured in the absence of the airfoil at the jet speeds, $v_{\mathrm{j}}$ of $33.3 \mathrm{~ms}^{-1}$ and $80 \mathrm{~ms}^{-1}$. The airfoil, with rough sandpaper placed near the leading edge on both the pressure and suction sides to trip the boundary layer into becoming turbulent, was then attached to the sidewalls and the measurement repeated at $v_{\mathrm{j}}=33.3 \mathrm{~ms}^{-1}$. The resulting narrowband noise spectra are plotted in Fig. 13b. Also shown in the figure are the predictions of trailing edge self-noise spectra obtained from the empirical prediction scheme developed by Brooks et al. [6] as well as the background noise. The result suggests that, in the low frequency range between $100 \mathrm{~Hz}$ and $400 \mathrm{~Hz}$, airfoil leading edge noise (triggered by the impingements of exit jet and the side plate turbulent boundary layers on the leading edge) and the side plate edge noise are the dominant noise sources. At higher frequencies, good agreement between the experiment result and Brooks et al.'s prediction is observed over the frequency range of $0.5-6 \mathrm{kHz}$, thereby confirming that the measured noise is predominantly trailing edge self-noise in origin. In this measurement the broadband trailing edge noise is seen to be more than $15 \mathrm{~dB}$ above the background noise level at the peak frequency of $1 \mathrm{kHz}$ and more than $10 \mathrm{~dB}$ at other frequencies.

The airfoil was then rotated to $10^{\circ}$ angle of $\operatorname{attack}^{\S}$ with the sandpapers near the leading edge of the pressure and suction sides removed. In this configuration noise tone produced by vortex shedding past the airfoil trailing edge is expected. The experiment was carried out at jet speed $v_{\mathrm{j}}$ of $80 \mathrm{~ms}^{-1}$ and the measured noise spectrum is also shown in Fig. 13b alongside the background and predicted airfoil noises. At this speed, the measured airfoil noise is still at least $10 \mathrm{~dB}$ above the background noise for all the frequencies. The deviation between the Brooks et al.'s trailing edge noise prediction to the measured airfoil noise below $2 \mathrm{kHz}$ is caused by the airfoil leading edge and the facility noises being more significant. The measurement however agrees well with the prediction at frequencies above $2 \mathrm{kHz}$. The trailing edge noise exhibits a broadband-"hump" between $3 \mathrm{kHz}$ and $7 \mathrm{kHz}$ with some discrete tones embedded. This type of spectrum in relation to a laminar airfoil is also observed by other researchers [20,21]. Peak frequency of the tone is visible at about $5 \mathrm{kHz}$ with $30 \mathrm{~dB}$ above the background noise level.

To provide a contour that vividly shows the footprint of the airfoil noise, the background noise and jet speed were first measured simultaneously as the flow speed was gradually reduced from its

\footnotetext{
$\S$ Due to the finite size of the open jet wind tunnel, the effective angle should be $2.8^{\circ}$ based on the wind tunnel correction scheme proposed by Brooks et al. [6].
} 
maximum value. This procedure was repeated with the airfoil installed at zero angle of attack (with sandpaper removed). Fig. 14a and b show, respectively, the contours of the sound pressure levels plotted as a colour map against frequency and flow speed without and with the airfoil. The resolution of the jet speeds presented in the figure is within $0.3-0.5 \mathrm{~ms}^{-1}$. While a low overall background noise level is observed (Fig. 14a), a distinct broadband-"hump" can be found for the case of trailing edge self-noise as well as the low frequency noise caused by the flow impingement to the airfoil leading edge at higher jet speeds (both indicated in Fig. 14b). When the results were compared with the Brooks et al.'s prediction scheme, although not shown here, both agree extremely well.

\section{Conclusions}

The design, construction and performance of a new quiet, low turbulence open jet blow down wind tunnel have been described. This facility is designed to achieve a maximum Reynolds number of $1.5 \times 10^{6}$ based on the hydraulic diameter of the nozzle. This paper presents the design principles underlying each component of the open jet wind tunnel. At the heart of the wind tunnel is a unique quiet control valve designed to reduce the valve noise caused by the large pressure drop across it. A large silencer with absorptive baffle plates is introduced downstream of the valve to further attenuate the valve noise present in the flow. A novel design feature of the wind tunnel is the use of a short $90^{\circ}$-curved diffuser in which a number of passive flow control devices were introduced in an attempt to inhibit boundary layer separation on the inner wall. The optimum combination of splitter vanes, honeycomb and woven wire mesh screens were determined after extensive experimentation on a scaled-down model of the $90^{\circ}$-curved diffuser. Further downstream of this was located a splitter silencer whose purpose is to settle down the flow and further attenuate the residual valve noise and any upstream boundary layer noise. The jet is finally accelerated through a 25:1 CR 3D nozzle in which air is discharged from the nozzle and into the anechoic chamber.

Detailed acoustic and aerodynamic measurements of the open jet wind tunnel are presented to assess the quality and performance of the wind tunnel. The results indicate that the facility has low background noise and that the free jet is aerodynamically clean with low turbulence intensity. Furthermore, the OASPL from the jet are as low, or lower, than many of the other aeroacoustic and automobile wind tunnels around the world. Finally, a benchmark test was performed by positioning in the free jet a NACA0012 airfoil with sandpaper tripping and measuring the corresponding trailing edge self-noise. The acoustics signals from the trailing edge were found to be substantially higher (by up $15 \mathrm{~dB}$ ) than the background noise levels. By removing the sandpapers on the airfoil, further test was conducted where tonal noise was clearly demonstrated. The wind tunnel is also 
being used to measure the self-noise from other bodies such as scale-models of high lift devices on aircraft and undercarriage components.

\section{Acknowledgement}

The work reported in this report is sponsored by the DARP MSTARR in the UK. The authors would like to thank John Coupland of Rolls-Royce for his helpful comments and supports throughout the project. The design and calculation of the primary silencer by Professor Alan Cummings at Hull University are greatly appreciated.

\section{Professor P. O. A. L. Davies - In Memoriam}

Professor Peter Davies, the co-author of this paper, passed away on February 2008 at the age of 85. He was one of the founders of the Institute of Sound and Vibration Research (ISVR) in the University of Southampton, UK. This paper is dedicated to his memory. Peter was an outstanding academic who worked on a wide range of aeroacoustic problems. We got to know and appreciate him as a kind, gentle and intelligent person. Apart from his professional help, he also became our personal friend. His passing is therefore not only a great loss to the department, but also a sad personal loss.

\section{References}

1. Amiet R. Noise due to Turbulent Flow Past a Trailing Edge. JSV, 1976; 47:387-393

2. Howe MS. Trailing Edge Noise at Low Mach Numbers. JSV, 1999; 225(2):211-238

3. Oberai AA, Roknaldin F, Hughes TJR. Computation of Trailing-Edge Noise due to Turbulent Flow Over an Airfoil. AIAA J., 2002; 40:2206-2216

4. Wang M, Moin P. Computation of Trailing-Edge Flow and Noise Using Large-Eddy Simulation. AIAA J., 2000; 38:2201-2209

5. Sandberg RD, Sandham ND, Joseph PF. Direct Numerical Simulations of Trailing-Edge Noise Generated by Boundary-Layer Instabilities. JSV, 2007; 304(3-5):677-690

6. Brooks TF, Pope DS, Marcolini MA. Airfoil Self-Noise and Prediction. Tech. rep., NASA Reference Publication 1218. 1989

7. Roger M, Moreau S. Broadband Self-Noise from Loaded Fan Blades. AIAA J., 2004; 42(3):536544

8. Ura H, Yokokawa Y, Ito T. Experimental Study of Trailing Edge Noise in Low-Speed Wind Tunnel. Collection of Technical Papers - $45^{\text {th }}$ AIAA Aerospace Sciences Meeting. 2007; 18:12536-12549

9. Duell E, Walter J, Arnette S, Yen J. Recent Advances in Large-Scale Aeroacoustic Wind Tunnels. $8^{\text {th }}$ AIAA/CEAS Aeroacoustic Conference and Exhibit, Breckenridge, Colorado. 2002; AIAA Paper 2002-2503

10. Mathew J, Bahr C, Sheplak M, Carrol B, Cattafesta LN. Characterization of an Anechoic Wind Tunnel Facility. Proceedings of ASME, IMECE, Orlando, Florida. 2005; IMECE2005-81737 
11. Leclercq D, Doolan C, Reichl J. Development and Validation of a Small-Scale Anechoic Wind Tunnel. $14^{\text {th }}$ International Congress on Sound and Vibration, Cairns, Australia. 2007

12. Coupland, J. (Rolls-Royce Plc), Private Communication

13. Cummings A. The Attenuation of Lined Plenum Chambers in Ducts: I. Theoretical Models. JSV, 1978; 61:347-373

14. Kline SJ, Johnston JP. Diffusers: Flow, Design, and Performance Prediction, Part 1: DiffuserFlow Phenomena and Design. Advanced topics in turbomachinery technology (PLS-2) (D. Japikse, ed.), Concepts ETI, Inc. 1986

15. Sagi CJ, Johnston JP. The Design and Performance of Two-Dimensional, Curved Diffusers. Trans. ASME, J. Basic Engng, 1967; 89:715-731

16. Chong TP, Joseph PF, Davies POAL. A Parametric Study of Passive Flow Control for a Short, High Area Ratio 90 Degree Curved Diffuser. Trans. ASME, J. Fluids Engng., 2008; 130:111104-1-111104-12.

17. Pinker RA, Herbert MV. Pressure Loss Associated with Compressible Flow through SquareMesh Wire Gauzes. J. Mech. Engng. Sci., 1967; 9(1):11-23

18. Bradshaw P. Wind Tunnel Screens: Flow Instability and Its Effect on Aerofoil Boundary Layers. Journal of Royal Aeronautical Society, 1964; 68:168

19. Kurze U. Sound Propagation in a Duct of Periodic Wall-Structure. Acustica, 1969; 21(2):74-85

20. Paterson RW, Vogt PG, Fink MR, Munch CL. Vortex Noise of Isolated Airfoils. J. Aircraft, 1973: 10:296-302

21. Arbey H, Bataille J. Noise Generated by Airfoil Profiles Placed in a Uniform Laminar Flow. JFM, 1983; 134:33-47 


\begin{tabular}{ccc}
$\begin{array}{c}\text { mass flow rate } \\
(\mathrm{kg} / \mathrm{s})\end{array}$ & $\begin{array}{c}\text { Exit jet speed } \\
(\mathrm{m} / \mathrm{s})\end{array}$ & $\begin{array}{c}\text { Running time } \\
(\mathrm{s})\end{array}$ \\
\hline 2 & 24 & 313 \\
4 & 48 & 156 \\
6 & 73 & 104 \\
8 & 97 & 78
\end{tabular}

Table 1 Summary of the open jet wind tunnel running time at different mass flow rates and exit jet speeds

\begin{tabular}{|c|c|c|c|c|}
\hline Honeycomb & Cell Diameter (mm) & Cell Length $(\mathbf{m m})$ & & \\
\hline $\mathrm{H}_{1}$ & 6.35 & 63.5 & & \\
\hline $\mathrm{H}_{2}$ & 6.35 & 63.5 & & $\boldsymbol{K}$ \\
\hline Screen & $\boldsymbol{D}(\mathbf{m m})$ & $\boldsymbol{P}(\mathbf{m m})$ & $\boldsymbol{\beta}$ & 2.0 \\
\hline $\mathrm{S}_{1}$ & 0.33 & 1.01 & 0.45 & 2.0 \\
\hline $\mathrm{S}_{2}$ & 0.33 & 1.01 & 0.45 & 1.5 \\
\hline $\mathrm{S}_{3}$ & 0.36 & 1.36 & 0.54 & 1.0 \\
\hline $\mathrm{S}_{4}$ & 0.4 & 1.7 & 0.58 & 1.0 \\
\hline $\mathrm{S}_{5}$ & 0.3 & 1.28 & 0.58 & \\
\hline
\end{tabular}

Table 2 Data for the honeycombs and screens used in the open jet wind tunnel. Refer to Fig. 1 for locations of the various honeycombs and screens 


\section{Stage I}

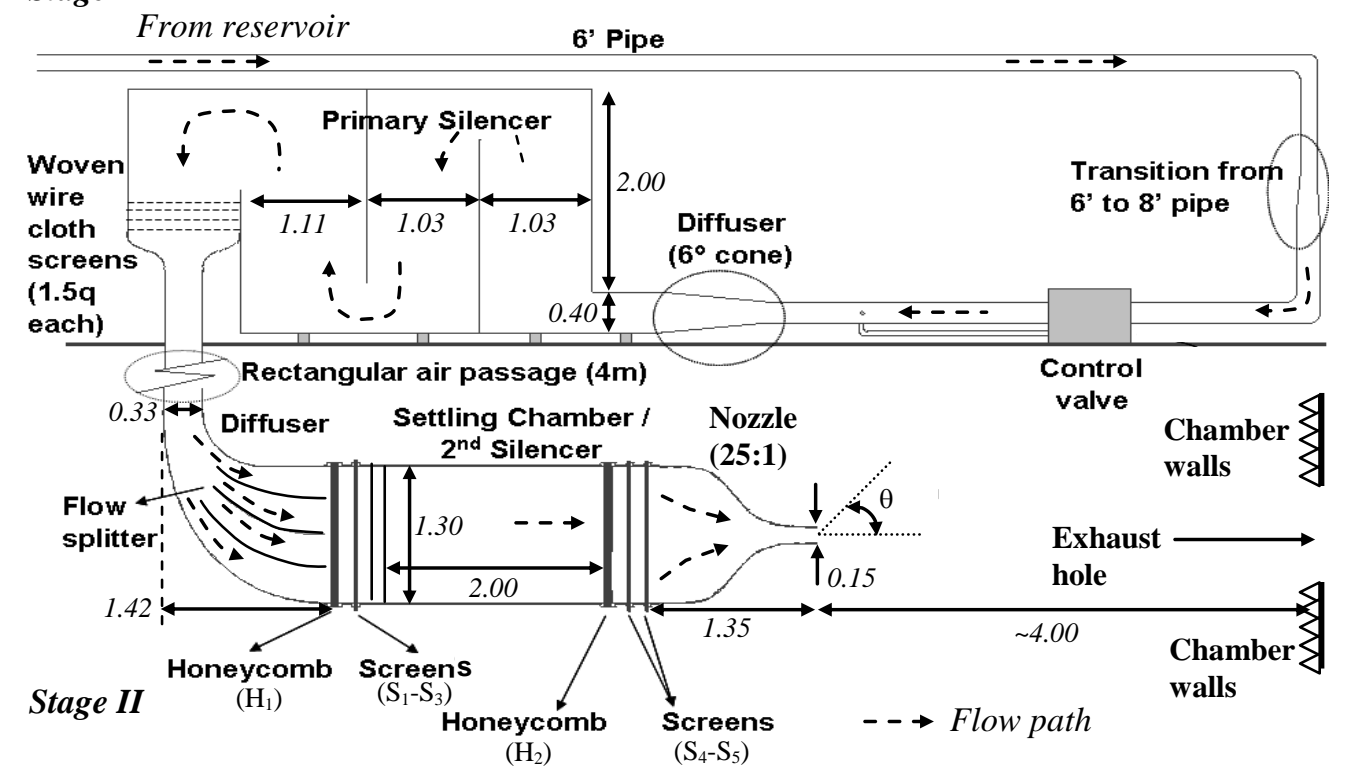

Fig. 1 Elevation view of the quiet, low turbulence blow down open jet wind tunnel in ISVR. All units in $\mathrm{m}$. 


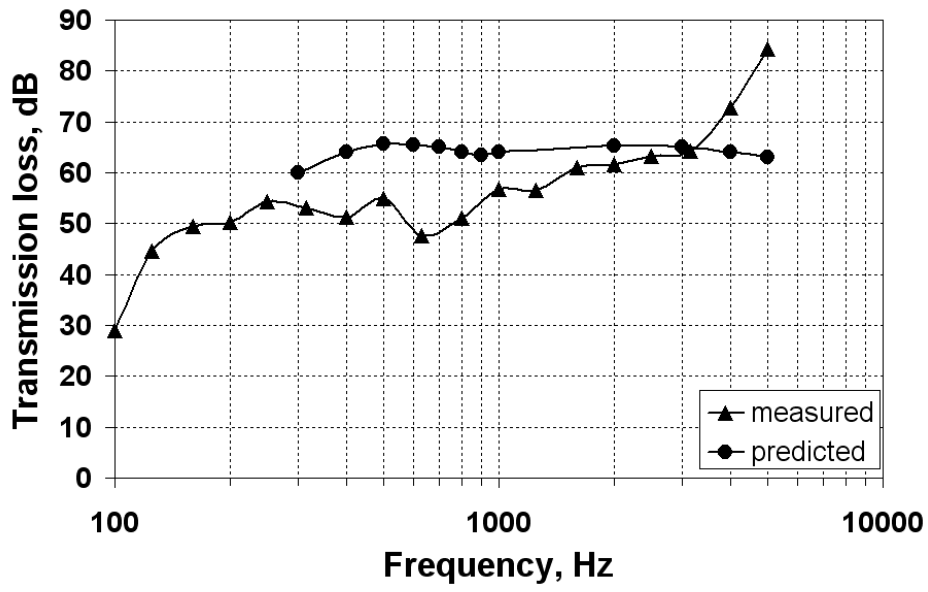

Fig. 2 Comparison of transmission loss between experimental results and theoretical estimation of the primary silencer. 
(a)

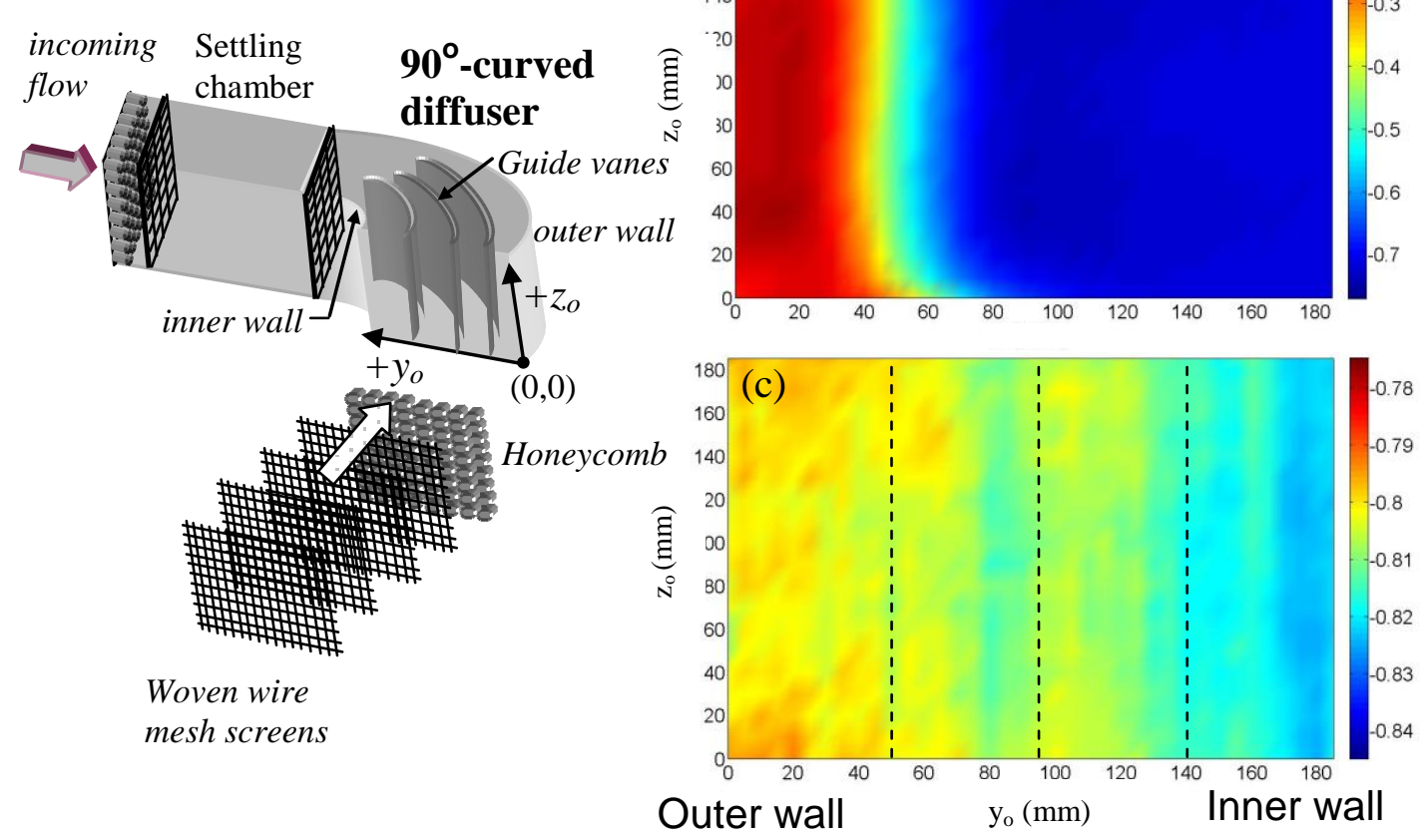

Fig. 3 (a). Schematic of the $90^{\circ}$-curved diffuser model for the flow control study. Coordinate system $\left(y_{o}, z_{o}\right)$ for the diffuser exit flow is also shown. Contours of exit pressure coefficient, $C_{p o}$ for the $90^{\circ}$-curved diffuser (a). without flow control, (b). with three guide vanes (location indicated by the vertical dash lines, also see Fig. 3a) and $5.5 q$ pressure drop at the exit. Negative values of $C_{p o}$ is caused by the discontinuity of total head between the reference and the measurement points as the result of flow through screens. 

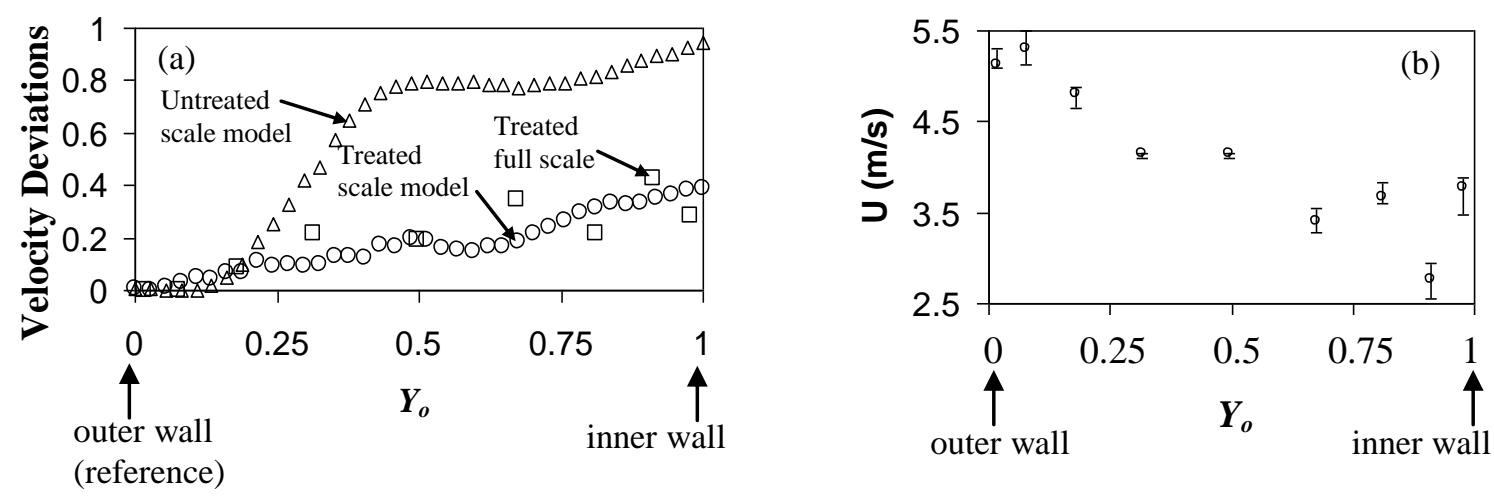

Fig. 4 (a) Comparison of velocity deviations from outer to inner walls at $Z_{o}=0.5$ of the $90^{\circ}$-curved diffuser exit for: 0 - treated scale-model, $\Delta$ - bare, untreated scale-model and $\square-$ treated full size $90^{\circ}$-curved diffusers; (b). Spanwise distributions $\left(Z_{o}\right)$ of exit velocity from the outer to inner walls of the full-size $90^{\circ}$-curved diffuser. 


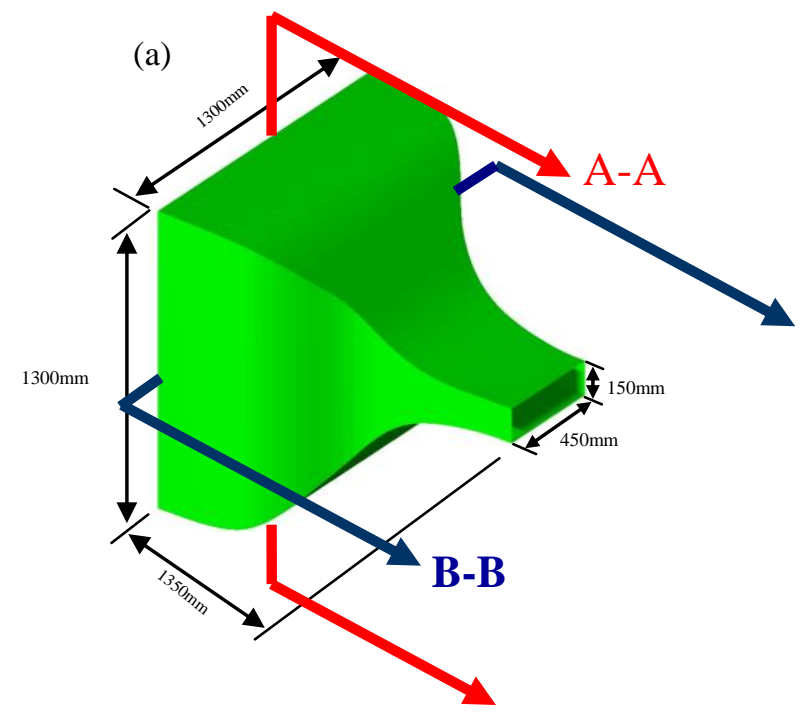

(b)

A-A $\quad$ B-B

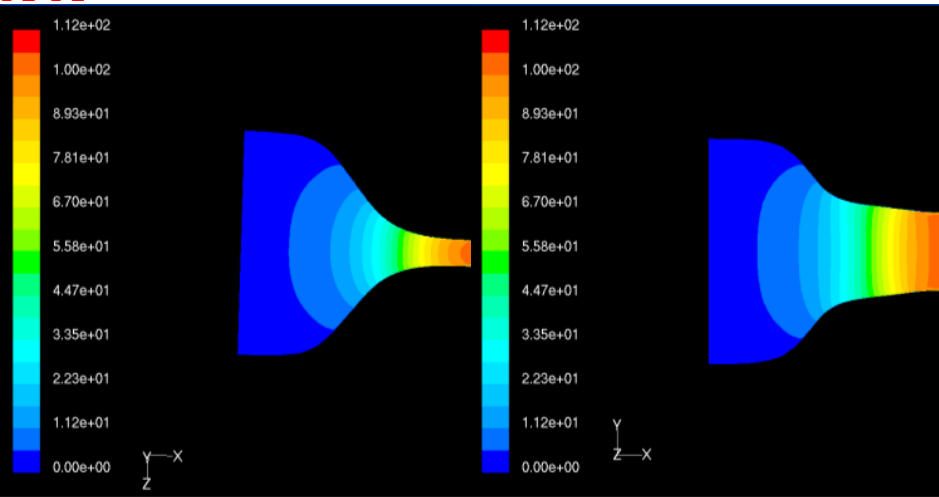

Fig. 5 (a). Isometric view of the 3D nozzle, (b). Numerical results of the flow field inside the nozzle, presenting velocity contours at A-A and B-B planes. 


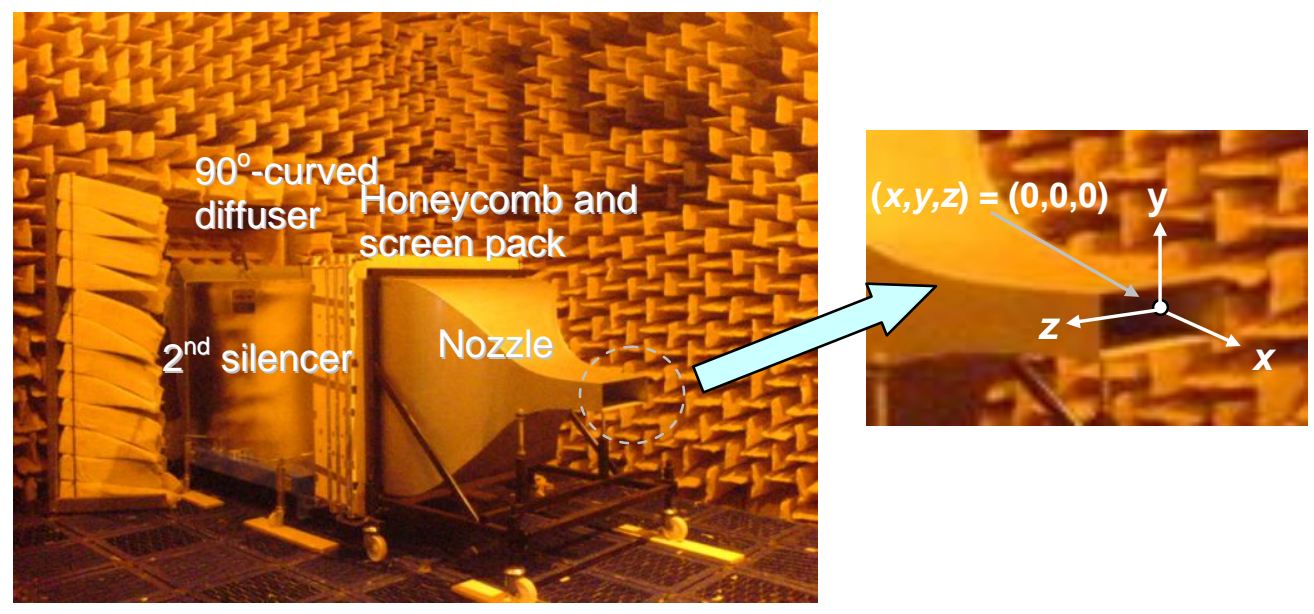

Fig. 6 Completed open jet wind tunnel in the ISVR's anechoic chamber. The new coordinate system $(x, y, z$-different from the diffuser case) in reference to the nozzle is shown in the smaller picture. 

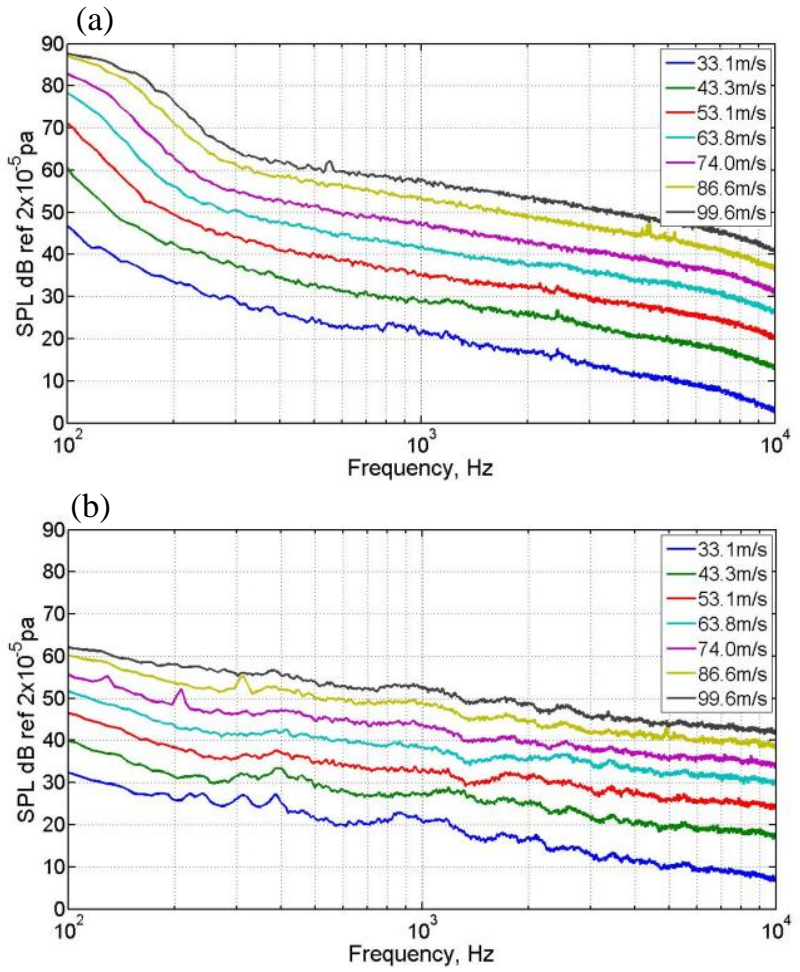

Fig. 7 Sound pressure level, $\mathrm{dB}$ (ref. $2 \times 10^{-5} \mathrm{pa}$ ) at $1 \mathrm{~Hz}$ bandwidth, $\Delta f=6.25 \mathrm{~Hz}$ of the open jet wind tunnel operated from jet velocities $33.1 \mathrm{~m} / \mathrm{s}-99.6 \mathrm{~m} / \mathrm{s}$. Spectra measured at (a). $\theta=45^{\circ}$, (b). $\theta$ $=90^{\circ}$. 


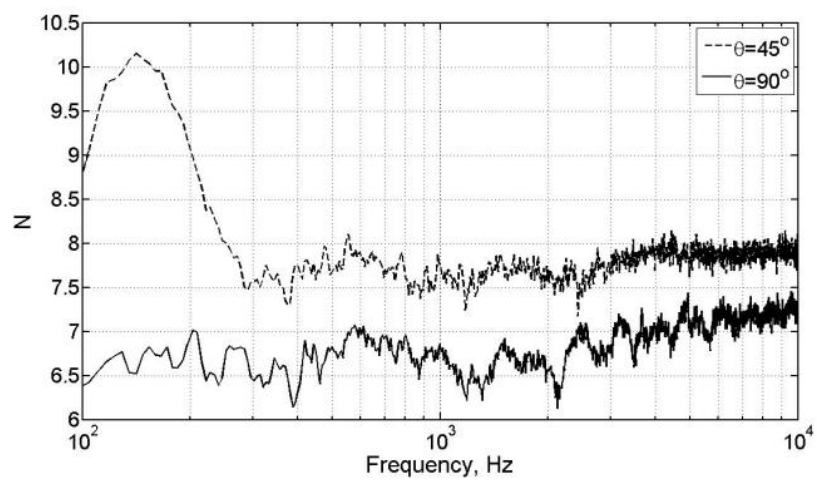

Fig. 8 Dependency of sound pressure level on jet velocity for --- $\theta=45^{\circ}$ and $-\theta=90^{\circ}$. Note that $N$ is the power factor of the velocity. 


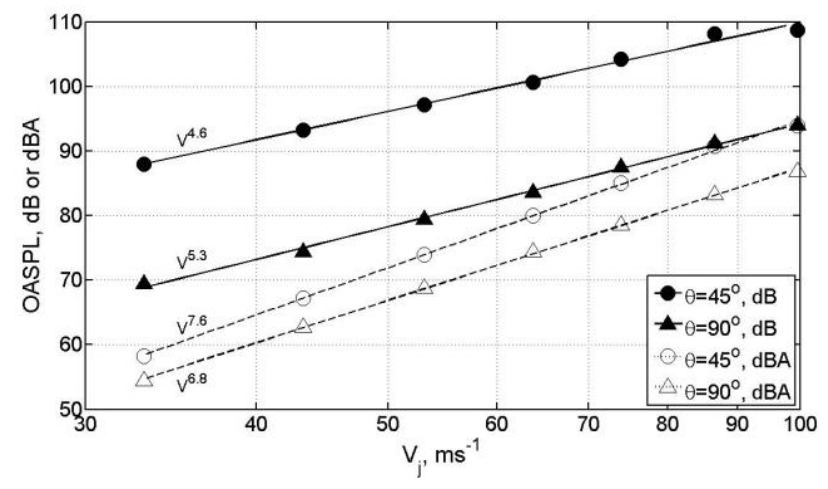

Fig. 9 Distributions of OASPL with jet velocity for $\theta=45^{\circ}$ and $90^{\circ}$. Power factors of the velocity $N$ are indicated for both of the $\mathrm{dB}$ and $\mathrm{dBA}$ cases. 


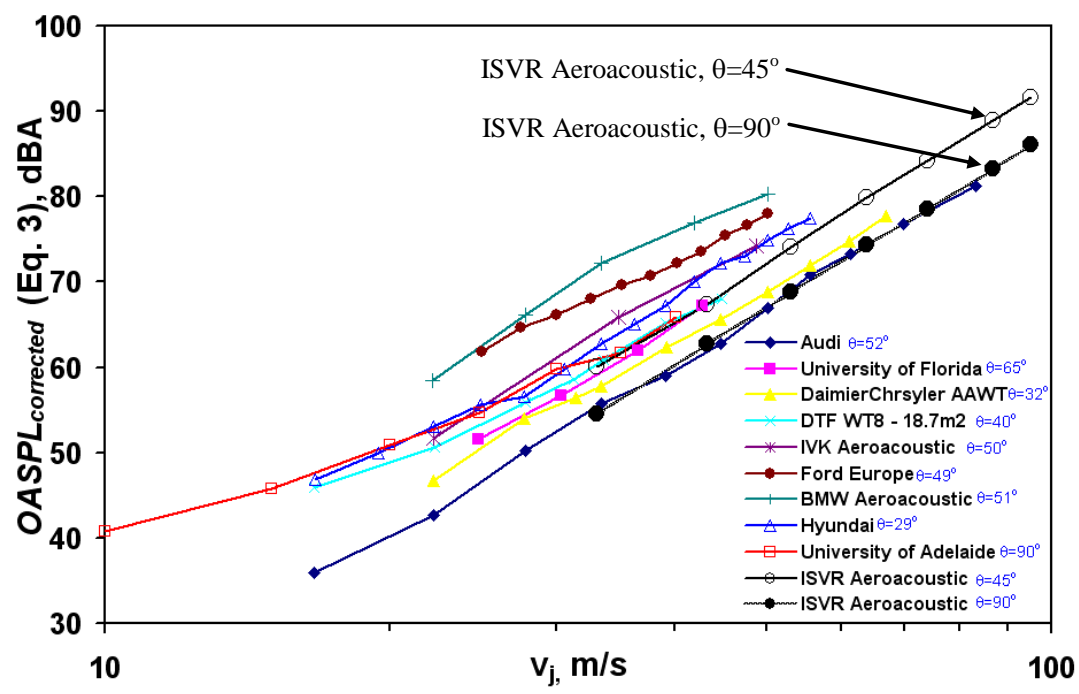

Fig. 10 Comparison of A-weighted OASPL (corrected by Eq. 3) background noise of the current open jet wind tunnel to other worldwide facilities. 
(a)
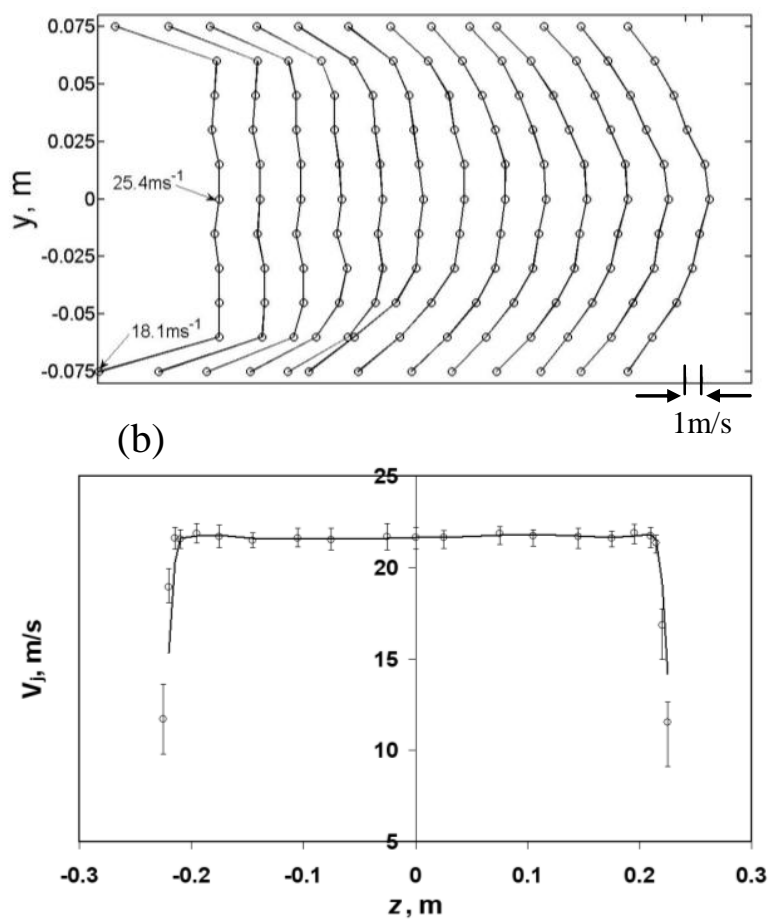

Fig. 11 (a). Velocity profiles in the $x-y$ plane at $z=0$. The velocity profiles starts at the left hand side of the figure from $x=0.1 \mathrm{~m}$ and to the right hand side of the figure at $x=1.3 \mathrm{~m}$ with $0.1 \mathrm{~m}$ increment, (b). Distribution of velocity profiles averaging across the $y$ axis at different spanwise location of the nozzle exit plane at $x=0.05 \mathrm{~m}$. Error bars corresponding to the maximum and minimum velocity deviations at each spanwise location are also shown. 


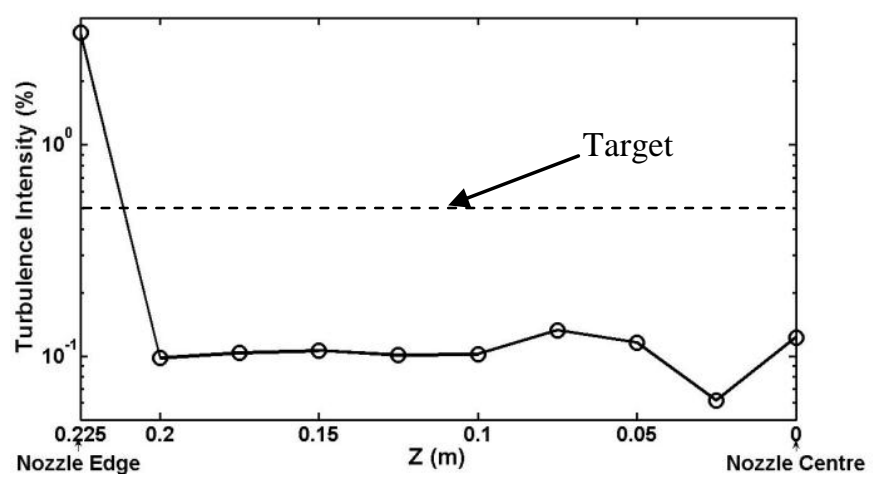

Fig. 12 Spanwise $(z)$ distribution of turbulence intensity of the exit jet at $60 \mathrm{~ms}^{-1}$ at $(x, y)=(0.1,0)$. 
(a)

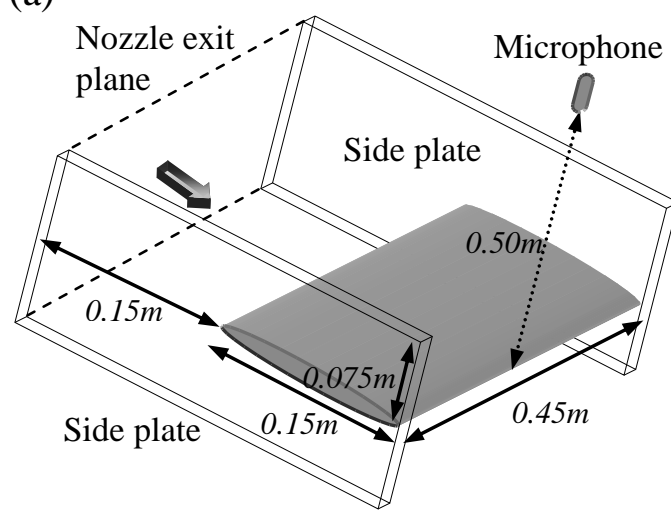

(b)

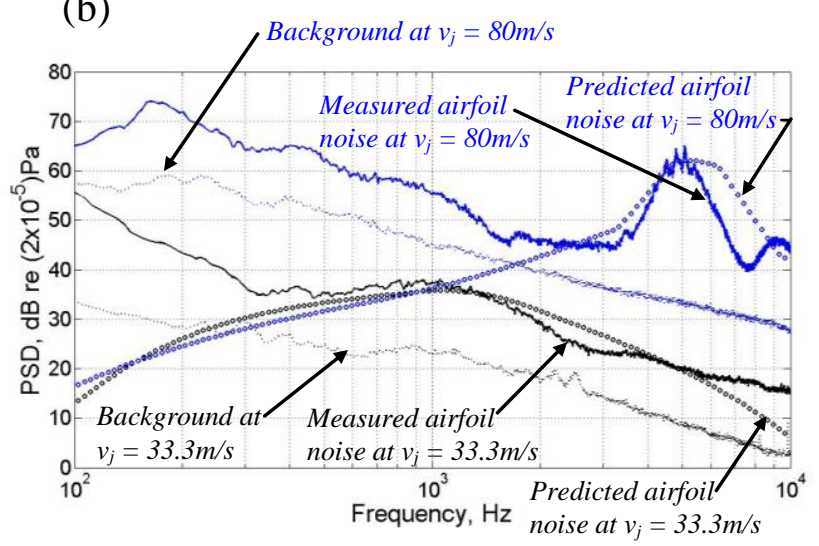

Fig. 13 (a). Schematic of the experimental layout of the airfoil trailing edge self-noise experiment using the ISVR aeroacoustic wind tunnel. (b). Comparison of PSD of the measured trailing edge noises at polar angle, $\theta$ of 90 degree for $v_{j}=33.3 \mathrm{~ms}^{-1}$ (tripped boundary layer at zero angle of attack) and $80 \mathrm{~ms}^{-1}$ (untripped boundary layer at $10^{\circ}$ angle of attack). The relevant spectra for the airfoil noise predictions by Brooks et al. and the facility background noises are also included for comparisons. 
(a)

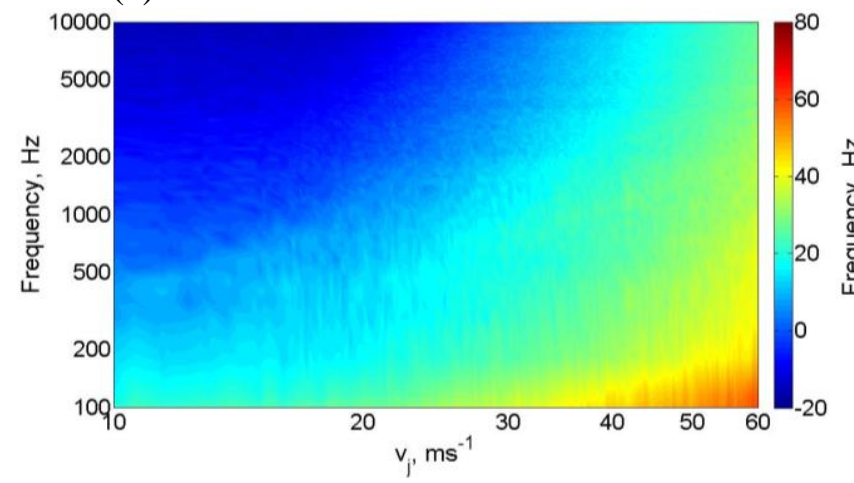

(b)

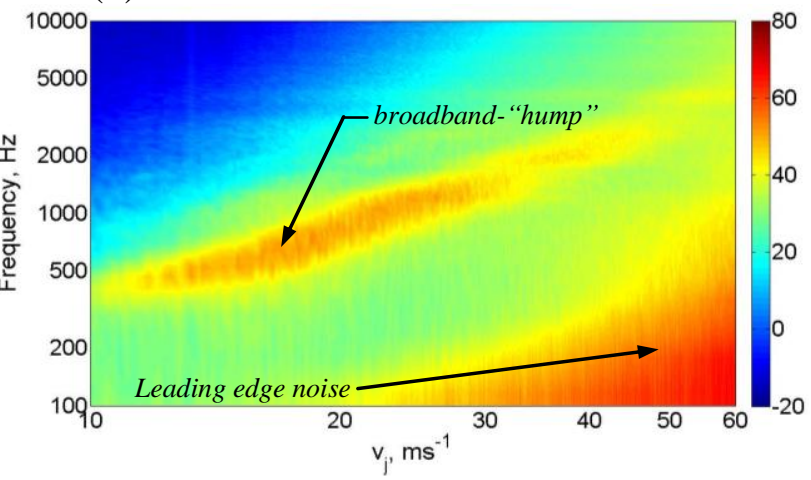

Fig. 14 Contours of the narrowband (spectra density) sound pressure levels in a frequency-jet speed domain (a). without and (b). with airfoil at zero angle of attack. 